\title{
Description of the Boundary Layer Behavior of an Aluminum-Carbon-Fiber-Reinforced Polymer Hybrid Compound Using a Cohesive Zone Model
}

\author{
Adrian Struß • Armin Schmid • Alireza Ebrahimi • Frank Jablonski • \\ Matthias Busse
}

Submitted: 7 May 2020/Published online: 3 June 2020

(c) The Author(s) 2020

\begin{abstract}
Compounds of light metals and fiber composites have a large potential in the field of lightweight construction. In order to fully exploit the properties of both materials, joining technology is a major challenge. One of the reasons for this is the electrochemical contact corrosion in these materials. By using a high-temperature resistant thermoplastic (PEEK) as a separating layer between the joining partners, it is possible to produce a material composite using the aluminum die casting process, which exhibits both electrochemical decoupling and high composite strength. The description of the failure behavior of this composite plays an important role in the application of this type of joint to structural components. One of the most widely used methods to describe the failure behavior of a composite using the finite element method is the cohesive zone model. With this model, the initiation of a crack, its evolution and finally the failure of the component can be described by means of a bilinear law. In this paper, a methodology to determine the necessary parameters for fracture mode I using a modified wedge test for the cohesive zone model is described.
\end{abstract}

\footnotetext{
A. Struß $(\bowtie) \cdot$ A. Schmid · M. Busse

University of Bremen, Bibliothekstraße 1, 28359 Bremen,

Germany

e-mail: adrian.struss@ifam.fraunhofer.de
}

A. Struß - A. Schmid - A. Ebrahimi - M. Busse

Fraunhofer Institute for Manufacturing Technology and

Advanced Materials IFAM, Wiener Straße 12, 28359 Bremen,

Germany

F. Jablonski

Bremen University of Applied Sciences, Neustadtswall 30,

28199 Bremen, Germany
Keywords Hybrid compound - Wedge test . Cohesive zone model

\section{Introduction}

Hybrid construction methods, in which (light) metals and composite materials are brought together, are regarded as promising lightweight construction strategies. In the implementation of these concepts, the focus is on the sensible combination of the two materials, which are aluminum and CFRP [1,2] in this case study. In the area of joining partners made of fiber composites, thermoset CFRP matrix systems exhibit disadvantageous properties such as brittleness, time-consuming production cycles and limited temperature resistance [3]. This makes them unsuitable for using in die casting process. Thermoplastic matrix systems such as polyetheretherketones (PEEK), on the other hand, have higher temperature resistance, toughness and the possibility to be produced faster [4]. Despite the high level of innovation used in production processes to achieve highly resilient and ultra-lightweight thermoset or thermoplastic CFRP structures and near-net-shape, economical die-cast aluminum components $[5,6]$, conventional mechanical or adhesive joining techniques are used in most cases for the manufacture of hybrid components made of aluminum and CFRP.

However, these joining techniques have several disadvantages. And this is why new types of joining technologies are being researched in different areas [7, 8]. For example, there may be changes in material properties within the heat-affected zone in welded joints or uneven stress transfer in the area of riveted joints [9]. Due to different material properties of the two materials, the joining technology for combining them plays a decisive role. The 
mechanical characterization of the boundary layer is also of decisive importance here [10].

In the present work, a methodology is developed to describe the failure behavior of a hybrid component made of aluminum and CFRP with a thermoplastic boundary layer under mode I loading, using the cohesive zone model. In addition to the performance of the fracture mechanical tests and the subsequent evaluation, the determination of the fracture mechanical parameters based on the test results is described. The focus of the subsequent analyses, which are performed using the commercial finite element software ABAQUS/Standard, was on the determination of the parameters of the cohesive zone model in order to ensure a high degree of agreement between the numerical model and the experimental results.

\section{Experimental Work}

The single-lap test specimens produced for the fracture mechanical tests are made of CFRP sheets with a length of $100 \mathrm{~mm}$, a width of $40 \mathrm{~mm}$ and a thickness of $1.55 \mathrm{~mm}$. These sheets are made of carbon fiber fabric and a PEEK matrix, partially coated with $(250 \mu \mathrm{m}$ thick $)$ films of PEEK. They are casted on one side with aluminum melt in a die casting process. The joining partner made of aluminum has the dimensions $100 \times 40 \times 10 \mathrm{~mm}$. The resulting material composite is shown in Fig. 1.

\section{Wedge Test}

One of the most widely used methods for identifying the constitutive parameters of the cohesive zone model is to perform crack propagation tests for the respective fracture modes [11]. A method for determining the adhesive properties of an adhesive bond of surface-treated aluminum sheets with standardized dimensions has been developed in the wedge test. This is carried out in a modified form in accordance with standard ASTM D3762 to determine the critical energy release rate for fracture mode I. For this purpose, samples of the hybrid composite (single-lap) were used which overlapped on one side. The thickness of the $40 \mathrm{~mm} \times 100 \mathrm{~mm}$ aluminum joining partners was $10 \mathrm{~mm}$. The CFK sheet metal with a thickness of $1.5 \mathrm{~mm}$ was cut off directly at the end of the overlap area. Between the two joining partners, the melted PEEK foil with a thickness of
$0.25 \mathrm{~mm}$ is located on the overlapping area with a size of $40 \mathrm{~mm} \times 40 \mathrm{~mm}$. Before clamping the aluminum joining partner, a crack of $2 \mathrm{~mm}$ length was made with a razor blade in the area where the wedge is to be driven in. A wedge with a width of $40 \mathrm{~mm}$, thickness of $6 \mathrm{~mm}$ and an angle of $30^{\circ}$ was then inserted into it at a speed of $5 \mathrm{~mm}$ per minute. The testing machine was used to measure the reaction force and feed path.

The setup is shown in Fig. 2.

\section{Modeling}

The experiments were modeled using ABAQUS. The mechanical model for investigating the delamination process is shown schematically in Fig. 3. The model consists of three bodies. The $40 \mathrm{~mm} \times 40 \mathrm{~mm}$ large and $1.55 \mathrm{~mm}$ thick CFRP sheet, which is connected to the $40 \mathrm{~mm} \times$ $40 \mathrm{~mm}$ large and $0.25 \mathrm{~mm}$ thick PEEK layer underneath by using a tie constraint. This in turn is connected via a cohesive zone with the underlying aluminum part with the dimensions $40 \mathrm{~mm} \times 10 \mathrm{~mm} \times 100 \mathrm{~mm}$.

Within the scope of the investigations, an elastic-plastic material model for the aluminum joining partner, an elastic material model for the PEEK boundary layer, and an orthotropic material model for the CFRP are used. The parameters of the material models are summarized in the following tables.

The discretization of the three components is done by continuum elements of type C3D8R. The C3D8R element is an eight node, three dimensional continuum stress/displacement element, with reduced integration. For the cohesive zone a surface-based interaction was selected.

Figure 3 shows the geometrical boundary conditions. Here, the nodes at the bottom of the composite are fixed in all directions. The displacement of the wedge is initiated at the back of the wedge using a reference point.

\section{Cohesive Zone Modeling}

The cohesive zone model [12-14] is one of the most widely used tools to describe fracture processes in interfaces. It can be used to describe the elastic behavior of the interface, crack initiation under load, crack propagation and complete failure of the interface for the respective fracture mode [15]. The surface-based damage model with bilinear constitutive law used here [16] is fully described by the

Fig. 1 Single-lap specimen 
Fig. 2 Principle sketch of the experimental setup

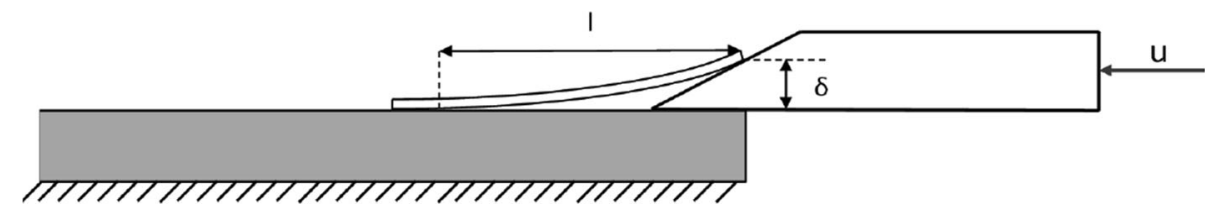

Fig. 3 Finite element model with boundary conditions

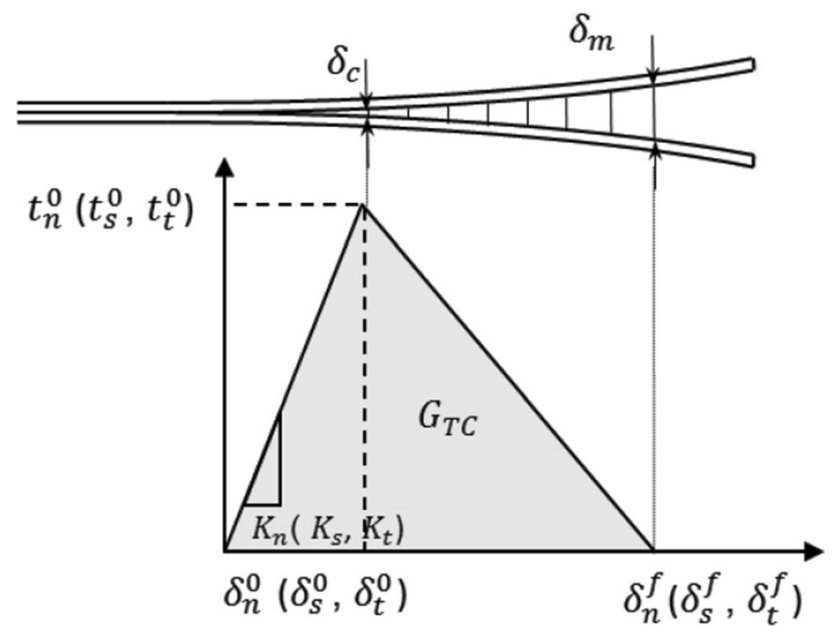

Fig. 4 Bilinear constitutive model

parameter $\mathrm{K}$, which describes the initial stiffness of the cohesive zone, the critical stress at crack initiation and the critical energy release rate. When the critical stress is reached, damage initiation begins. As soon as the critical separation is reached, the boundary layer is completely separated. Figure 4 shows a typical traction-separation response with a failure mechanism.

The damage initiation is described in the following investigations by a quadratic nominal stress criterion as follows.

$\left\{\frac{\left\langle t_{n}\right\rangle}{t_{n}^{0}}\right\}^{2}+\left\{\frac{t_{s}}{t_{s}^{0}}\right\}^{2}+\left\{\frac{t_{t}}{t_{t}^{0}}\right\}^{2}=1$

Here $t_{n}, t_{s} t_{t}$ are the values of tensile or shear stresses which are necessary for the failure of the cohesive layer under pure tensile load or pure shear load. The symbol \langle\rangle represents the Macaulay bracket. It is used to describe that compressive stresses do not cause damage. The relative displacement between the top and the bottom of the cohesive layer is described by the components $\delta_{n}, \delta_{s}$ and $\delta_{t}$. The relationship between the stresses $t_{i}$ and separations $\delta_{i}$ $(i=n, s, t)$ for each failure mode can be expressed as follows.

$t_{i}=K_{i} \delta_{i}$

where $K_{i}(i=n, s, t)$ defines the stiffness of the interface for each failure mode.

Once failure has occurred, damage evolution begins. The damage is described using the variable $D$. Once the criterion of Eq. (1) has been reached, the cohesion stiffness $K$ decreases. The damage variable $\mathrm{D}$ now increases until it reaches the value $D=1$ for a completely fractured interface $d=1$. In case of a linear softening process the damage variable $d$ can be expressed by the maximum value of mixed mode displacement $\delta_{m}^{\max }$ and the total mixed mode displacement $\delta_{m}$.

$D=\frac{\delta_{m}^{f}\left(\delta_{m}^{\max }-\delta_{m}^{0}\right)}{\delta_{m}^{\max }\left(\delta_{m}^{f}-\delta_{m}^{0}\right)}$,

The total mixed mode displacement $\delta_{m}$ is calculated by Eq. (4).

$\delta_{m}=\sqrt{\delta_{n}^{2}+\delta_{s}^{2}+\delta_{t}^{2}}$

The effect of the damage variable $D$ on the contact stresses is shown in Eqs. (5)-(7).

$t_{n}=\left\{\begin{aligned}(1-D) \bar{t}_{n}, & \bar{t}_{n} \geq 0 \\ \bar{t}_{n} & \end{aligned}\right.$

$t_{s}=(1-D) \bar{t}_{s}$

$t_{t}=(1-D) \bar{t}_{t}$

The contact stresses $\bar{t}_{n}, \bar{t}_{s}$ and $\overline{t_{t}}$ are the stress components predicted by the traction separation approach for the current undamaged state of the interface.

The damage evolution is described using an energy criterion. The proposed approach of Benzeggagh and Kenane [17] is particularly well suited for the damage evolution in the field of epoxy and PEEK composites, which has already been shown in investigations by Camanho [16]. In Eq. (8), $G_{\mathrm{c}}$ describes the critical fracture energy for mixed mode fracture. The fracture toughness for 
each single mode is identified by $G_{\text {Ic }}, G_{\text {IIc }}$ and $G_{\text {IIIc }}$. The exponent $\eta$ describes the relationship between the single failure modes and is typically determined in a mixed mode bending test. According to [16], it is selected to 1.45 .

$G_{\mathrm{c}}=G_{\mathrm{Ic}}+\left(G_{\mathrm{IIc}}-G_{\mathrm{Ic}}\right)\left(\frac{G_{S}}{G_{T}}\right)^{\eta}$

where

$G_{S}=G_{\text {IIc }}+G_{\text {IIIc }}$

and

$G_{T}=G_{\mathrm{Ic}}+G_{S}$

Parameter Identification

To determine the critical energy release rate, various approaches such as the modified beam theory or the Compliance Calibration Method [18] are used in the literature. Common to all of them is the need for experimentally determined force-displacement curves of

Table 1 Material properties of Aluminum and PEEK used for the model

\begin{tabular}{lcl}
\hline & $E(\mathrm{GPa})$ & $v$ \\
\hline Aluminum & 74.2 & 0.3 \\
PEEK & 3.8 & 0.36 \\
\hline
\end{tabular}

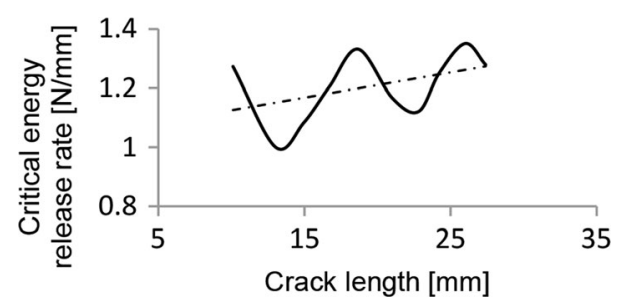

Fig. 5 Critical energy release rate as a function of crack length

Table 2 Material properties of CFRP used for the model

\begin{tabular}{cccc}
\hline & $E_{1}(\mathrm{GPa})$ & $E_{2}(\mathrm{GPa})$ & $G_{12}(\mathrm{GPa})$ \\
\hline CFRP & 54.8 & 13.3 & 15.1 \\
\hline
\end{tabular}

the composite and the optically recorded crack propagation during the tests.

Sener et al. [19] showed that the critical energy release rate can be determined in a wedge test by considering the peeled joining partner as a beam clamped on one side and subjected to a point load. The crack openings $\delta$ and crack lengths $l$ measured in the wedge tests together with the stiffness EI of the CFRP sheet metal result in the elastic work $U$ stored in the beam according to [20].

$U=\frac{3 \mathrm{EI}+\delta^{2}}{2 l^{2}}$

Thus, the energy stored in the CFRP sheet increases with increasing deflection. With further crack propagation, this energy is again reduced. This can be described by the critical energy release rate, which can be determined according to [21] as follows

$G_{c}=-\frac{1}{b} \frac{d U}{2 l^{3}}=\frac{9 \mathrm{EI} h^{2}}{2 b l^{4}}$

With the material properties from Table 1 , the width $b$ of the sample the crack openings and crack lengths measured in the test at different times of crack propagation, the critical energy release rate over the progressive crack length results as follows.

Due to the optical measuring method, it is only possible to quantify the deflection of the CFRP sheet metal from a crack length of $10 \mathrm{~mm}$. The crack opening is measured up to a crack length of $30 \mathrm{~mm}$. In this range of crack propagation the critical energy release rate for mode $\mathrm{I}$ is calculated. In Fig. 5 it is shown that this fluctuates in the range of $1 \mathrm{~N} / \mathrm{mm}$ up to $1.3 \mathrm{~N} / \mathrm{mm}$. This can be attributed to the inaccuracies in the measurement of crack opening and crack length (Table 2).

According to [16] the initial stiffness was chosen $K=$ $10^{6} \mathrm{~N} / \mathrm{mm}^{3}$ for each failure mode. The critical energy release rate of $1.2 \mathrm{~N} / \mathrm{mm}$ was chosen on the basis of the results from Fig. 5. In order to fully describe fracture mode I, the critical fracture stress must be determined.

Determining the fracture stress from this type of test method is difficult, so further fracture mechanical tests are necessary. Therefore, in most cases, these parameters are fitted so that they correspond to the test results [11] (Fig. 6).

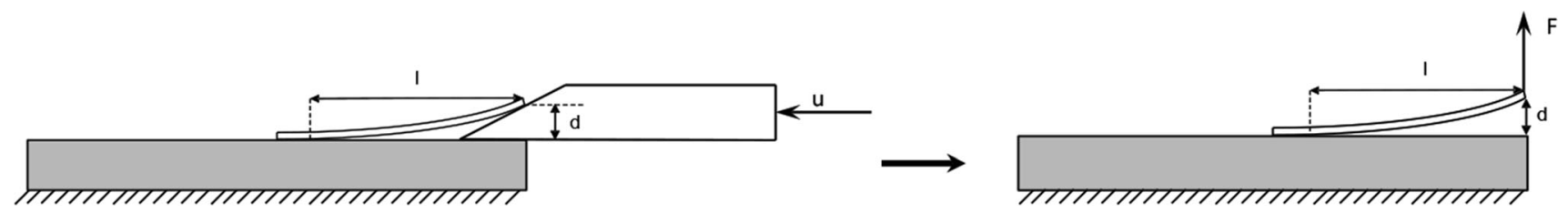

Fig. 6 Equivalent model for determining the vertical force 
To determine the fracture stress, the vertical force responsible for the peeling process as well as the deflection of the organic sheet is determined using the beam theory. In the simulation, a displacement is applied at the contact point of the wedge to the organic sheet. The failure stress was then adjusted so that the measured reaction force at the contact point of the wedge in the simulation corresponds to the previously calculated forces from the experiment (Fig. 7).

Afterward, the coefficients of friction of the contact pairings aluminum/steel or CFRP/steel were determined or adjusted using the measured reaction force on the wedge from the experiments and the simulation. The reaction

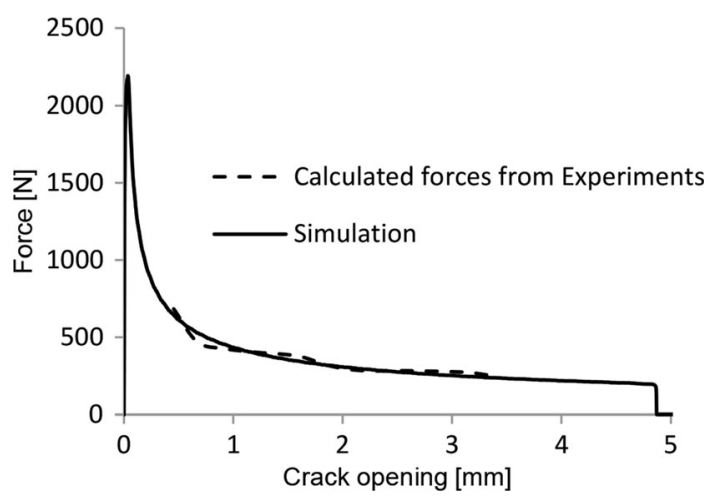

Fig. 7 Calculated vertical force from experiments/vertical force from simulation

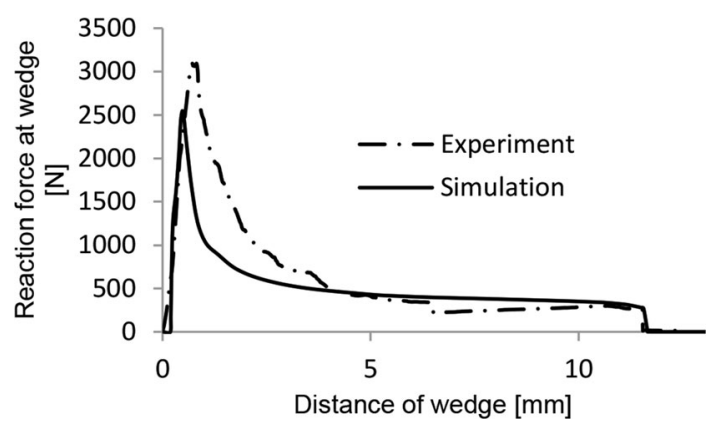

Fig. 8 Force-displacement curves: experiment/simulation force on the wedge was then compared with the experimental measurement results in the simulation. The comparison of the force-displacement curves is shown in Fig. 8.

Figure 8 shows clearly that the measured force up to the failure occurrence in the experimentally determined curve rises at a slightly flatter rate than the calculated curve from the simulation. This can be explained by the settlement behavior of the machine and the test specimens. The maximum force is also slightly higher in the experimentally determined curves than in the calculated curves from the simulation. However, the damage evolution over the remaining fracture surface shows a very good agreement between experiment and simulation.

Figure 9 shows the comparison of the failure mechanism of simulation (b)) and experiment (a)). It can be seen, that both the deformation of the CFRP sheet by the wedge and the peeling process show good agreement.

\section{Summary}

In order to describe the failure behavior of a hybrid composite of CFRP and aluminum under quasi-static load, the finite element method was used. We introduced a surfacebased cohesive zone model with a bilinear traction-separation approach. For the cohesive zone model, the critical energy release rate for fracture mode I was identified using quasi-static investigations on modified wedge test specimens. The approach of [21] was used for this purpose. Furthermore, the critical fracture stress for mode I was adjusted so that the results of the experiments and simulation showed good agreement. In summary, it can be said that it is possible to determine the critical energy release rate for fracture mode I of the hybrid composite analyzed here using the wedge test. By adjusting the breaking stress in the normal direction, the experimental results can be well reproduced. This becomes clear by comparing the failure progress of experiment and simulation. In the case of damage initiation, however, there are some differences which can be explained by a non-ideal positioning of the wedge in the experiment. Due to the previous assumptions
Fig. 9 Wedge test: a) experiment, b) simulation

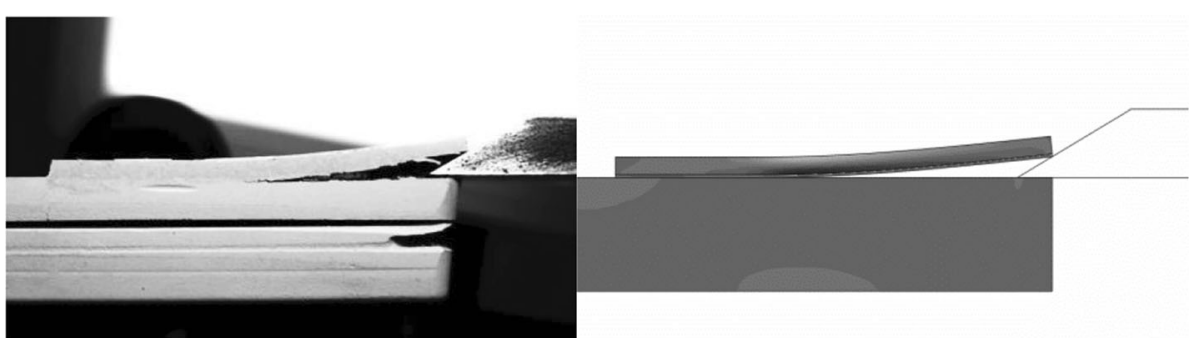

(a)

(b) 
of the fracture mechanical parameters for fracture modes II and III, these must be determined in further experiments.

Acknowledgment Open Access funding provided by Projekt DEAL. The authors gratefully acknowledge the Deutsche Forschungsgemeinschaft (DFG) for their financial support.

Open Access This article is licensed under a Creative Commons Attribution 4.0 International License, which permits use, sharing, adaptation, distribution and reproduction in any medium or format, as long as you give appropriate credit to the original author(s) and the source, provide a link to the Creative Commons licence, and indicate if changes were made. The images or other third party material in this article are included in the article's Creative Commons licence, unless indicated otherwise in a credit line to the material. If material is not included in the article's Creative Commons licence and your intended use is not permitted by statutory regulation or exceeds the permitted use, you will need to obtain permission directly from the copyright holder. To view a copy of this licence, visit http://creativecommons. org/licenses/by/4.0/.

\section{References}

1. H.E. Friedrich, S.K. Krishnamoorthy, Leichtbau als Treiber von Innovationen, in Leichtbau für den Fahrzeugbau, ed. by H.E. Friedrich (Springer, Wiesbaden, 2013), pp. 1-30. (in German)

2. L. Hagebeuker, K. Seidel, L. Eckstein, Composite-intensiver Leichtbau in Fahrzeugmodulen, Automobil technische Zeitschrift, edition 11, 2016, p 30-35 (in German)

3. S. Cao, Z. Wu, X. Wang, Tensile properties of CFRP and hybrid FRP composites at elevated temperatures. J. Compos. Mater. 43(04), 315-330 (2009)

4. F.N. Cogswell, Thermoplastic Aromatic Polymer Composites (Butterworth-Heinemann Ltd., Oxford, 1992)

5. E. Brunhuber, Praxis der Druckgußfertigung (Schiele \& Schön, Berlin, 1992)

6. O. Diestel, J. Hausding, Vorimprägnierte textile Halbzeuge (Prepregs), C. Cherif, Textile Werkstoffe für den Leichtbau (Springer, Berlin, 2011), pp. 381-401

7. P. Kah, R. Suoranta, J. Martikainen, C. Magnus, Techniques for joining dissimilar materials: metals and polymers. Rev. Adv. Mater. Sci. 36, 152-164 (2014)
8. S.T. Amancio-Filho, J.F. dos Santos, Joining of Polymers and Polymer-Metal Hybrid Structures: Recent Developments and Trends, Polymer Engineering and Science, 2009, p 1461-1476

9. W. Brockmann, P.L. Geiß, J. Klingen, K.B. Schröder, Adhesive Bonding: Materials Applications and Technology (Wiley, Weinheim, 2008)

10. X. He, A review of finite element analysis of adhesively bonded joints. Int. J. Adhes. Adhes. 31, 248-264 (2011)

11. R. Kießling, F. Hirsch, C. Dammann, M. Bobbert, M. Pohl, M. Kaestner, Hybrid metal-composite interfaces: aspects of design, characterisation, and simulation. Adv. Mater. Res. 1140, 255-263 (2016)

12. D.S. Dugdale, Yielding of steel sheets containing slits. J. Mech. Phys. Solids 8(2), 100-104 (1960)

13. G. Barenblatt, The mathematical theory of equilibrium cracks in brittle fracture. Adv. Appl. Mech. 7, 55-129 (1962)

14. A. Hillerberg, M. Modéer, P.-E. Petersson, Analysis of crack formation and crack growth in concrete by means of fracture mechanics and finite elements. Cem. Concr. Res. 6(6), 773-782 (1976)

15. M. Elices, G.V. Guinea, J. Gómez, J. Planas, The cohesive zone model: advantages, limitations and challenges. Eng. Fract. Mech. 69, 137-163 (2002)

16. P.P. Camanho, C.G. Davila, M.F. de Moura, Numerical simulation of mixed-mode progressive delamination in composite materials. J. Compos. Mater. 37, 1415-1438 (2003)

17. M.L. Benzeggagh, M. Kenane, Measurement of mixed-mode delamination fracture toughness of unidirectional glass/epoxy composites with mixed-mode bending apparatus. Compos. Sci. Technol. 49, 439-449 (1996)

18. P.A. Gustafson, A.M. Waas, The influence of adhesive constitutive parameters in cohesive zone finite element models of adhesively bonded joints. Int. J. Solids Struct. 46, 2201-2215 (2009)

19. J.-Y. Sener, T. Ferracin, L. Caussin, F. Delannay, On the precision of the wedge-opened double cantilever beam method for measuring the debonding toughness of adhesively bonded plates. Int. J. Adhes. Adhes. 22(2), 129-137 (2002)

20. S. Timoshenko, J.N. Goodier, Theory of Elasticity (McGraw-Hill, New York, 1970)

21. G.R. Irwin, J.A. Kies, Critical energy rate analysis of fracture strength. Weld. J. 33(1), 193-198 (1954)

Publisher's Note Springer Nature remains neutral with regard to jurisdictional claims in published maps and institutional affiliations. 